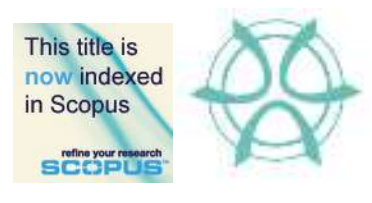

PLANNING MALAYSIA:

Journal of the Malaysian Institute of Planners

VOLUME 18 ISSUE 4 (2020), Page 62- 79

\title{
THE IMPACT OF PHYSICAL FEATURES AND ENVIRONMENT ON CRIME IN URBAN NEIGHBOURHOOD AREAS
}

\author{
Fazzami Othman', Zaharah Mohd Yusoff ${ }^{2}$, Siti Aekbal Salleh ${ }^{3}$ \\ ${ }^{1,2,3,}$ Faculty of Architecture, Planning and Surveying \\ UNIVERSITI TEKNOLOGI MARA (UiTM)
}

\begin{abstract}
The physical design of features and environment will stimulate a safe and sustainable development of the neighbourhood. Despite possessing a proper form, a private space which does not control and keep could even raise fear and crime incident. Therefore, this study planned to analyse the fear, perception and potential feature that caused the crime event in neighbourhoods. Three years of burglary data got from the Royal Malaysia Police helped to explain the crime trend and pattern. Besides, a statistical analysis conducted to examine the fear level and perception towards crime incident using a set of questionnaires. Next, the potential features and visibility level examined in the unit of a house that has experienced the burglary event. The purpose is to find any element that can affect crime event. Results prove that actual crime data not associated with fear and perception of the crime. Besides, accessibility, visibility and crime pattern were the key elements to consider for crime prevention.
\end{abstract}

Keywords: Environmental design, fear of crime, security, urban space

${ }^{1}$ PhD candidate at UiTM. Email: fazzamiothman@gmail.com 


\section{INTRODUCTION}

Security and urban design are connecting to form a sustainable and safe city. The outrageous demand of resident to settle in a safe place leaves to several initiatives by Malaysia's government to satisfy. In advance, a safe city program set up to promote public safety by enforcing a strategy of crime prevention through environmental design. The idea is to prevent and reduce the fear of crime from the practical design of the physical environment. Besides, it also rises with the quality of life and reduction of cost. According to Cozens and Love (2015), the efficiency of design by completing natural strategies can reduce costs and resources compared to the management and mechanical approaches to security. Through efficient design, safety can build up for recent development. This approach has put natural surveillance and visibility to form a splendid view from various angles, thus lessening the opportunity of a crime event. Space with reduced clarity and promotes obstruction can affect to the rising level of fear.

There is often a mismatch between levels of crime and the fear of turning into a victim of crime. A place might show an increase in crime and sometimes an odd level of the crime rate. The problem is that fear of crime persists unchanged, even though the crime rate is low. Fear of crime contributes to those who are more prosperous to defend themselves and their property. It depends on many factors, perhaps the most obvious being an actual crime. At a micro-level, it thought people who experience crime also encounter more fear and, at a macro-level, that location which has been a place for criminal activity also acknowledged being less secure and could be a potentiality of a repeated event. Previous analysis of the fear of crime has already shown significant outcomes. For instances, women and older people saw more insecure, poor people direct to turning into a victim, and that knowing some familiarity with the area felt more safe than unfamiliar.

The purpose of this study was to analyse the fear and perception with the environment factors towards crime in two case study in the public place. Several objectives set up to fulfil the study aim, such as, to analyse the crime trend and pattern in both neighbourhoods, to identify the fear level and perception towards crime event in the neighbourhood, and to examine the potential features and measure the visibility level that can affect burglary event. A set of questionnaire and site inventory produced based on several aspects include offence-specific fears, expected risk of victimisation, and preventive crime measure.

\section{RESEARCH BACKGROUND}

Designing a proper layout believed in cutting fear of crime. Any space with high visualisation and natural surveillance can raise a confidence level to survive. Public space needs to maximise visibility and natural surveillance for limiting the crime event. The statement emphasised in crime prevention through 
Fazzami Othman, Zaharah Mohd Yusoff, Siti Aekbal Salleh

The Impact of Physical Features and Environment on Crime in Urban Neighbourhood Areas

environmental design (CPTED) while utilising it as one of the major components. The CPTED formed in the early 1970s as a response to an increase in crime and fear in urban areas (Marzbali, 2019). With extending the quality of the environment and life, CPTED based on design and physical environment that understand affecting human behaviour. It is a multidisciplinary approach to deterring criminal behaviour that concentrates on how space has placed, how it looks and feel. Several cities have applied to the concept of CPTED such as New York, Glasgow, Adelaide, Melbourne, Seoul and Singapore; and it has convinced to weaken the crime rate (JPBD, 2014).

Burglary and street crime in an area of South Los Angeles have shown a downer when thousands of people show up to the farmer market. According to Ryan (2014), CPTED works well in reduction by increasing the movement using a fence opening and public art in a crime hot spot. The purpose is to develop natural surveillance on open space, therefore reducing the opportunity of crime events. Consistent research on urban space against crime has conducted by several researchers (Piza et al., 2019; Kim et al., 2019; Rosser et al., 2017). The study utilised the principle of CPTED to diagnose the effectiveness of crime prevention and reduction. As a result, the visibility of space reduces the crime rate and fear of crime. Besides, an obscure vision of the surrounding area serves to a false interpretation of potential criminal; thus, stimulates the secure opportunity of being a victim. According to Patterson (2016), the barriers and access in the layout should control and maintain to avoid any disrupting phenomenon referred to the crime. The best way is to produce a visible space by encouraging natural surveillance. Likewise, in Malaysia, CPTED implementation guideline is one initiative taken by Town and Country Planning Peninsular Malaysia (PLANMalaysia) to control the layout design. Apart from encouraging an active social movement throughout the public space, this initiative also emphasises several development components, including layout design, by providing clear, maximised and unobstructed view of the area at short and longdistance. Massive pillars, fences that are not transparent, maintained shrubs and other obstacles in public space can create hideouts for criminals to threaten the public.

According to Summers and Johnson (2017), any potential movement, people, and space are one of the configuration characteristics related to the crime occurrence. The reason is that any enclosed space could remain a place for criminals to execute a crime so-called an opportunity. As asserted by Lis et al. (2019), walking with greater visibility, no hiding place and more accessibility in a public area perceived as less dangerous, less opportunity and more preferred. The findings suggest that the landscape have to shape, so it does not provide any place to hide, therefore feel safe. People wish to see and know what happens on in their environment. Physical feature and environment such as vegetation, building design and orientation, potential features (stairs, utility poles, trees or 
grilles) may influence the visibility and increases opportunity. For example, with burglary, the chance to carry out crime exposed when there is easy access to entry at the back lane. Any potential features that located nearer to the dwelling can encourage criminal activity.

A study by Lee and Ha (2016), which identified the effect of visibility on fear of crime within elementary schools, urged capturing and consider the curvature of the surface, on the natural environment and human-made. The angle and distance of visibility are the essential elements that influenced the fear among student. A spotted area with many hiding places raises the fear level of most children in school. Besides, visibility associated fear of crime on human behaviours. The finding supported by Schroeder et al. (2015), where building height, facade or as the change in the surface's topography, would allow researchers to more significant in the study of urban space. It is because any curvature in design could limit the human visual, thus tricky to offer an unobstructed view either from or toward nodes of location. Besides, there is a long tradition of addressing crime in problem areas by removing vegetation for a better view of surveillance. Though, the landscape facilitates crime because it can hide the sight from view. This finding, supported by Du and law (2016), suggested that the tree canopy and crime index has correlated in waterloo, USA. As mention, most of the study agreed to promote the idea where excellent visibility increases the safety level and reduce the fear of crime, in the public area.

Crime events are more likely to happen when there is a suitable target, predicted the temporal activity of people, spatial and temporal confluence of motivated offenders and targets, along with no capable guardians (Bruinsma \& Johnson, 2018). The travel patterns and routine activity on weekdays vary compared to the weekend (Brantingham \& Brantingham, 2017). Previous research also shows crime concentrates in unique places on weekdays and weekends (Malleson \& Andresen, 2015; Ceccato \& Uittenbogaard, 2014). However, the studies proposed that several elements, such as land used, routine activity, and layout design, could be the cause. The sensible of a crime event have to match the actual crime data. The reason is that any potential of criminal opportunity is growing from the mismatch somehow produced the fear of crime.

\section{RESEARCH METHOD}

\section{Scope of the Study}

This study focuses on the relationship between fear and perception with the environment factors towards crime. The widespread distribution of burglary and varied property crime rate in the neighbourhood has led to considering the social aspect of perception and preventives action taken. Several elements discussed in literature adopted for the conceptual design of this study, as illustrated in Figure 1. It is essential to distinctions and organises the flow of work, so that achieved the aim. Primary elements such as criminal and target, the impact of the physical 
Fazzami Othman, Zaharah Mohd Yusoff, Siti Aekbal Salleh

The Impact of Physical Features and Environment on Crime in Urban Neighbourhood Areas

environment and urban neighbourhood; clarified in the earlier study used to find the potential caused of fear towards crime. The relationship between these principles has delivered to several components that need to analyse.

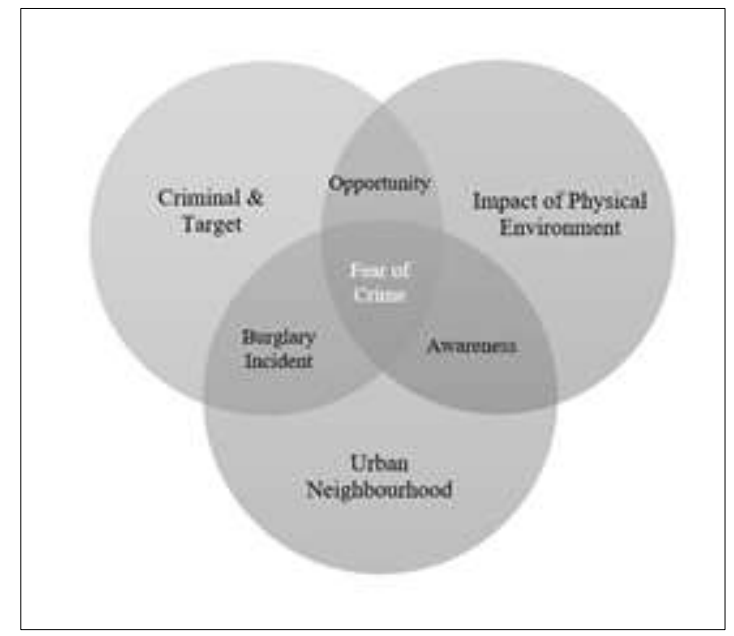

Figure 1: The conceptual design of the study

Several elements have examined by the inventory based on the profile, accessibility (to enter the house) and visibility of home. The inventory focused on the house that experienced the burglary event with an emphasis on the opportunity formed from the environment factor. The criteria of accessibilities, visibility, potential features and preventive measure verified on-site, based on the CPTED implementation guideline by PLAN Malaysia. Also, this study conducted a questionnaire survey for the evaluation of fear towards crime in each neighbourhood. The study reviewed the assessment based on the several aspects such as respondent background, security aspect, fear of being a victim, the comfort of the house, quality of life and security of the house. It then analyses crime data in the resident neighbourhood referred to the perception and fear of crime.

\section{Case Study}

Property crime considered being high risk in Malaysia while Kuala Lumpur reported the highest crime density based on the population. Fast development has raised the crime rate in a particular area in Damansara-Petaling municipal. Because of the top crime event on burglary, this study selected Taman Gembira and Taman OUG as a case study area. Burglary recorded 140 cases during three consecutive years of 2015 to 2017 in both neighbourhoods. The number does not cover the other crime which has stated in the same period-estimated around 4,000 households in compromise to be a victim if these criminal issues are yet in 
doubt to prevent. Besides an occupied area, with placed and surrounded in by strategic land use, this neighbourhood gave better and outrageous demand for housing development. Figure 2 pictures the view of the study area in the Google satellite image.

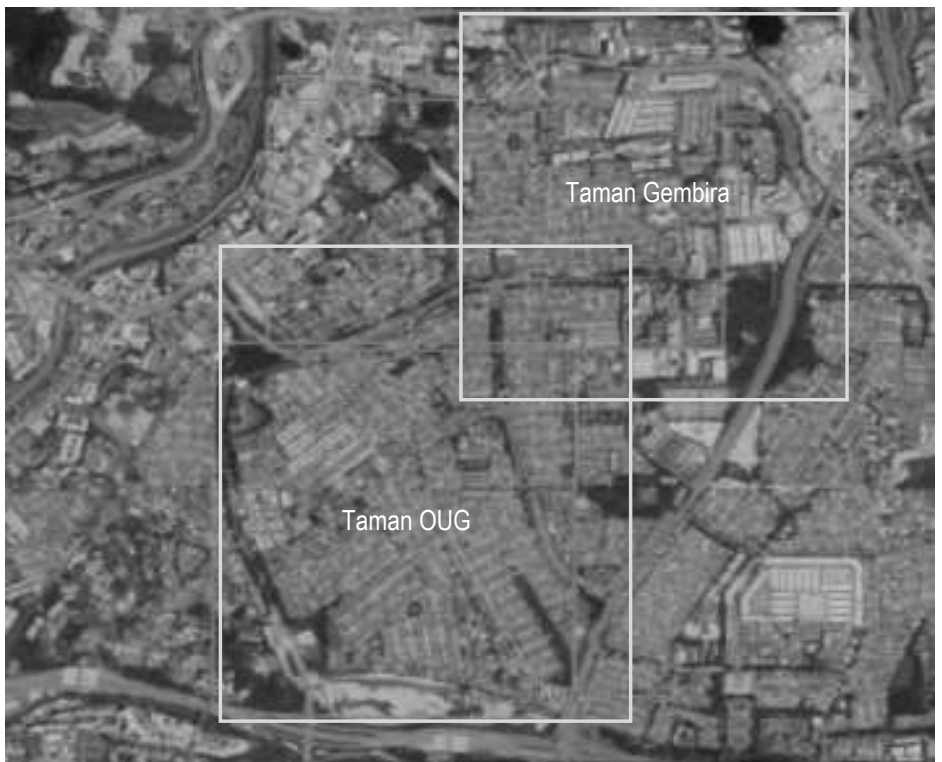

Figure 2: The case study area at the Petaling municipality of Kuala Lumpur Source: Google (2020)

\section{Questionnaire Survey and Housing Inventory}

Based on the Department of Statistic Malaysia, during 2019 the average household size in Malaysia recorded as 4.0. It is the multiple numbers used to calculate the sampling based on the verified housing unit. This study chose an equal amount of sampling based on probability sampling method, with 383 respondents recorded from Taman OUG and 369 from Taman Gembira. The onground questionnaire survey carried out amid 2019. A sequent number of questions asked based on the questionnaire form design in the cloud. According to Shamsudin et al. (2013), this technique is the overt way to measure the level of thinking, behaviour, emotions and individual behaviour. The actual fear of respondent towards the security and environment expressed by asking about what they feel, think, do and done, then complement to the purpose of this questionnaire survey. In specific, the study conducted to collect and understand the fear of being a victim in their neighbourhood. The sample covered both male and female, with various age groups and socio-economic background.

Besides, housing inventory has operated to investigate the potential cause of burglary event. Based on the burglary dataset that has gained from the 
Fazzami Othman, Zaharah Mohd Yusoff, Siti Aekbal Salleh

The Impact of Physical Features and Environment on Crime in Urban Neighbourhood Areas

Royal Malaysia Police (RMP), 81 cases reported in Taman OUG while 60 cases in Taman Gembira. The burglary occurred in $85 \%$ on terrace houses from 2015 to 2017. Among the affected homes, around $76 \%$ (92 nos) of them chosen as an inventory, which carried out alongside a questionnaire survey. The sampling calculation based on $\mathrm{p}=.05$ where the probability of committing a type I error is less than $5 \%$, or $\mathrm{p}<.05$. Purpose of the inventory is to explore and identify the potential feature that can cause an opportunity for the criminal to enter. Inventory form designed based on the respondents' perception and to comply with CPTED implementation guideline which focused on accessibility, visibility and security.

\section{Method of Analysis and Interpretation}

This study analysed the data using the frequencies, Pearson's chi-squared test, and cross-tabulation to investigate the level of fear, security and perception on crime. Besides, multi-response test of regression has used to determine the effectiveness of CPTED. The purpose is to understand the resident's perception of the actual crime event in their neighbourhood area. It also examines the relationship between visibility level with the environment factors towards crime. Meanwhile, the quantitative analysis conducted using the statistical test of descriptive because of the numeric and the data associated with accuracy.

\section{THE RESULT AND FINDINGS}

This study has started with connecting the respondent questionnaire and burglary data in hourly duration. The perception of burglary, event and level of fear was underlying data belief for analysing the respondent's perception in this study. Based on the result, midnight hours influenced most of the respondents' perception of the safety level in the neighbourhood. As stated in Table 1, 77\% of respondent in Taman Gembira consider the higher risk of burglary arises from 1 am to $5 \mathrm{am}$. In contrast, most of the respondent feel safe during the evening when only $2 \%$ presume the burglary event to take action. This pattern was showing the same as the respondent in Taman OUG, where only 3\% proposes the same result. Besides, $82 \%$ of respondent showed the burglary took action during midnight. Based on the crime data gained from RMP, most of the burglary event took place from 0800 to 1000 and late evening of 1800 to 2200 . However, the figure produces a declined burglary rate during midnight for each neighbourhood, as shown in Figure 3. 
PLANNING MALAYSIA

Journal of the Malaysia Institute of Planners (2020)

Table 1: The expected interval of burglary event based on respondents' perception

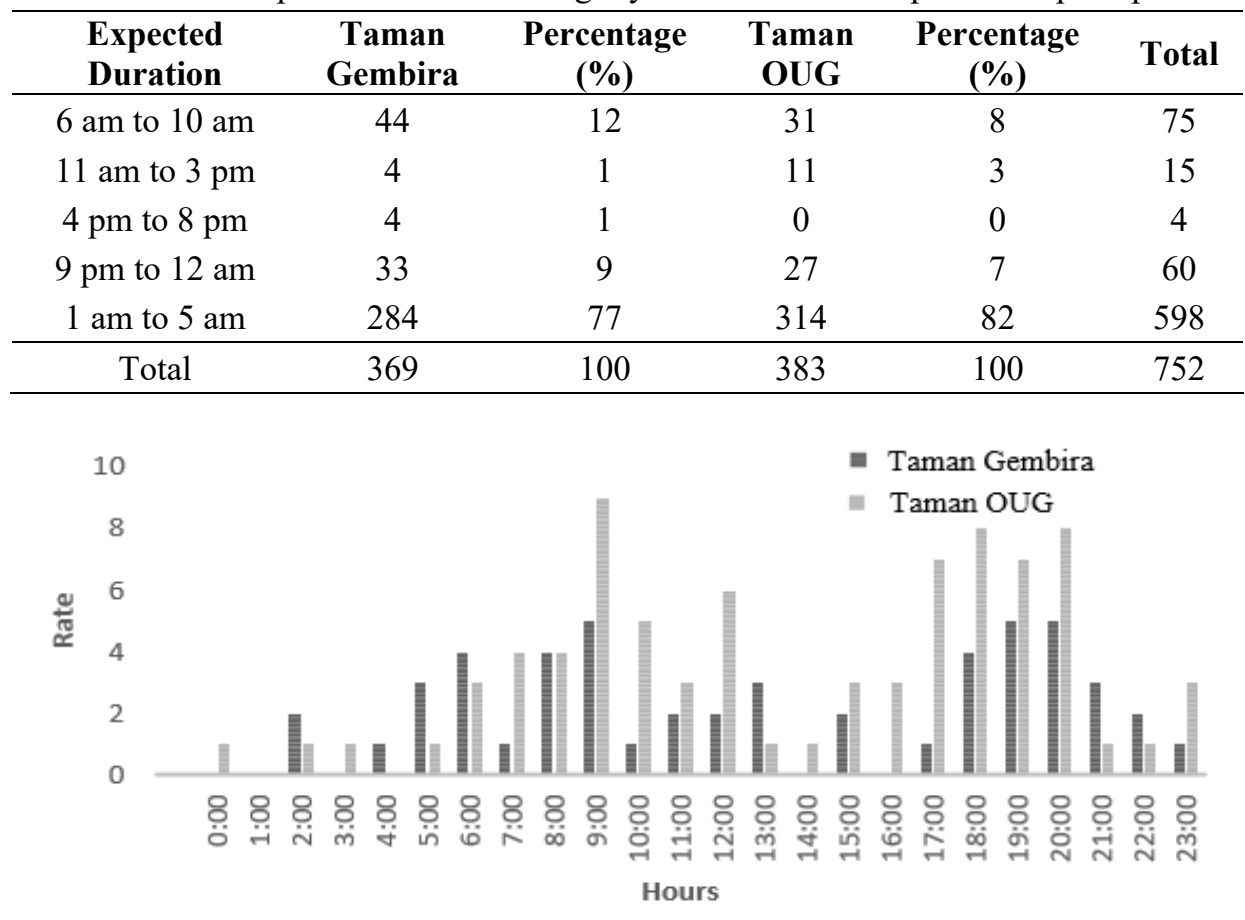

Figure 3: Hourly incidents of burglary for Taman Gembira (A) and Taman OUG (B) Source: Royal Malaysia Police (2018)

Based on the hourly event of a burglary, there is an explicit assumption that the incident is taking place when there are no people inside the house. As the routine activity, people are working during the day while living at home during midnight. The offender intended to operate with no disruption and harmful them too. It supported by a statement released by Town and Country Planning of Peninsular Malaysia (PLANMalaysia) in a social medium through sources from Royal Malaysia Police, where the crime rate, including the residential burglary, has dropped during the Movement Control Order (MCO). There are 127 cases, recorded, dropped $68 \%$ from a usual total average of 395 cases (many crimes) per day. The dropped can explain the declination through some theories of the safe city such as rational choice, routine activity, and lifestyle approaches. Based on the crime concept, criminal select the potential target before any action made. Besides, from a criminal perspective, on getting a return, there is a higher risk of escaping and requires more effort to commit the crime. Criminal, also tricky to observe the potential target, as people have changed their forms of living by staying at home. 
Fazzami Othman, Zaharah Mohd Yusoff, Siti Aekbal Salleh

The Impact of Physical Features and Environment on Crime in Urban Neighbourhood Areas

Despite having shown the same pattern in both neighbourhoods, but the respondent's perception towards actual burglary data, as shown in Figure 3, is wrong. The other elements that influence the wrong perception may nurture the fear level of the respondent. Thus, this study prepared scale level questions of fear figuring a better visualisation of the wrong perception towards a regular event and how safe they feel to live in that area. Based on the outcome, all respondent feels worried if the house has broken in within the next 12 months (Table 2). They show it that the burglary has influenced the level of fear across a unique background of people. It is because burglary not only affects the economy but can also disturb life.

Table 2: Level of Fear towards burglary event

\begin{tabular}{lccccc}
\hline \multirow{2}{*}{ Fear of Crime } & \multicolumn{5}{c}{ Number of respondents } \\
\cline { 2 - 6 } & \multicolumn{4}{c}{$(1=$ worried/unsafe; 5 } & calm/safe) \\
\cline { 2 - 6 } & 1 & 2 & 3 & 4 & 5 \\
\hline Worried on having broken in within & 744 & 8 & nils & nils & nils \\
the next 12 months & $(99 \%)$ & $(1 \%)$ & & & \\
\hline Worried when stranger approaching & 301 & 210 & 158 & 68 & 15 \\
the house & $(40 \%)$ & $(28 \%)$ & $(21 \%)$ & $(9 \%)$ & $(2 \%)$ \\
\hline \multirow{2}{*}{ Feel safe when entering the house } & 60 & 286 & 353 & 53 & \multirow{2}{*}{ Nil } \\
\hline \multirow{2}{*}{ Feel Safe staying alone } & $(8 \%)$ & $(38 \%)$ & $(47 \%)$ & $(7 \%)$ & \\
\hline \multirow{2}{*}{ Feel Safe staying during the day } & 158 & 263 & 331 & nils & nils \\
\hline \multirow{2}{*}{ Feel Safe staying during the night } & $(21 \%)$ & $(35 \%)$ & $(44 \%)$ & & 8 \\
& 38 & 579 & 98 & 30 & 8 \\
\hline
\end{tabular}

Nowadays, people concerned if a stranger is approaching the house. As shown in Table 2, it affected the respondent feeling in both neighbourhoods, where $40 \%$ seem worried, followed by $28 \%$ of less worried and $21 \%$, which is not either worried or calm. The scale indicators also used to determine the fear level either inside or outside of their occupied unit house. Based on the result, most of the respondent in both study area is feeling secure during at home, either staying alone or access in and out; however, period change (day and night) affects their level of fear. As shown in Table 2, almost $81 \%$ of respondent feel safe when staying during the day while $15 \%$ during the night. This result shows a solid pattern towards the perception of burglary event early. Perhaps, the mild and deeper environment during the night, which limit the viewpoint, caused the increase of fear level and caused to the incorrect perception against regular burglary cases. 
The physical design of the environment may influence the fear of crime or the crime rate. In this study, the housing inventory executed on both neighbourhood areas with an emphasis on the affected units that have experienced burglary events. The purpose is to have the design's information thought to change the crime distribution. The inventory was prepared based on crime prevention through environmental design (CPTED) implementation guideline. Several prevention elements in CPTED implementation guideline that assigned to the housing unit got for the inventory test. The strategies are to investigate the incorporated element of surveillance, such as natural and mechanical surveillance. Natural surveillance facilitated through the design of space, provision of landscape, and housing orientation included window and doors. Besides, mechanical surveillance facilitated through the use of electronic and mechanical equipment such as lighting, CCTV, burglar alarm, and others. The inventory started by reviewing the mechanical surveillance and preventive measure applied to each unit of houses which had an experienced to the criminal event. The purpose is to examine the perception level by considering the initiatives taken to prevent burglary or any crime event. In CPTED, it encourages the security device to provide area or place without possible visualise space, a potential existing area that threatened to crime, and any entrapments area. Based on the result, as shown in Figure 4, at least one mechanical surveillance and preventive measure apply to each unit of the house as an effort to limiting the criminal event.

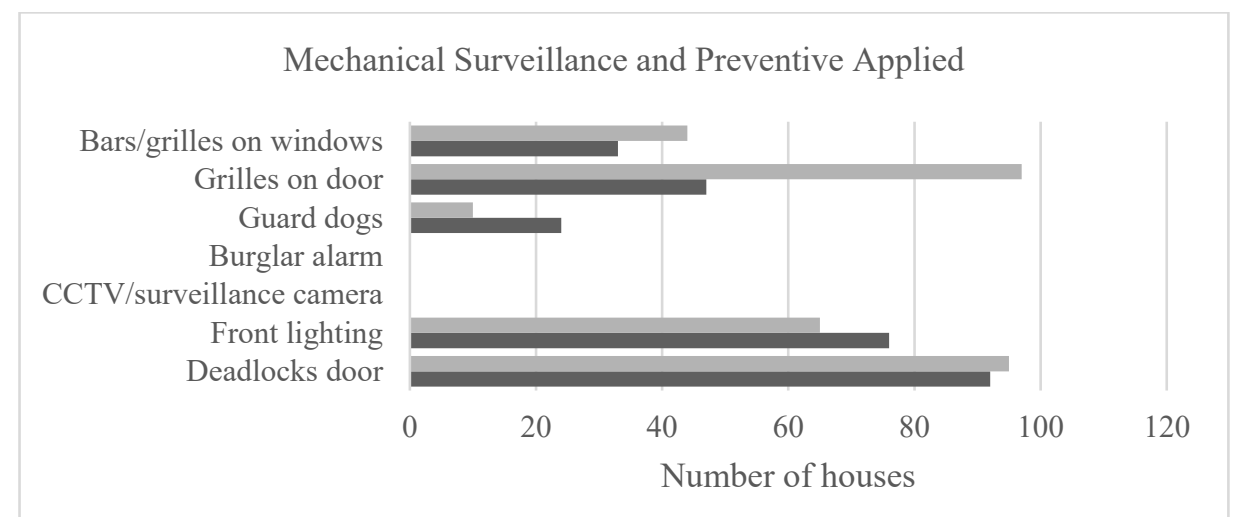

Figure 4: Mechanical surveillance and preventive applied in both neighbourhoods

Most of the housing units in both neighbourhoods provided deadlocks door and front lighting while Taman OUG more likely used grilles on the door as a protective measure compared to Taman Gembira. Also, 97 units have applied the additional preventive measure by a door's grilles for easy installation and higher security as entry-hardening. For the lighting, $70 \%$ of the unit has equipped, 
Fazzami Othman, Zaharah Mohd Yusoff, Siti Aekbal Salleh

The Impact of Physical Features and Environment on Crime in Urban Neighbourhood Areas

while some depend on the street-lighting. The most affected target-hardening such as CCTV and burglar alarm not implemented as the household background is a middle-income earner. The cost of installation and maintenance, the reason for not being installed. There are yet lacks mechanical surveillance served by each unit. As shown, only half from the affected unit on both neighbourhoods applied bars or grilles on windows. Apart from doors, windows too could be the primary access for the criminal to infiltrate. It is a component made with an easy broken, breaks, and secure entry when the elevation allowed a criminal to pass over.

For the best crime prevention, mechanical and natural surveillance implemented in an integrated manner, with priority given to the natural surveillance at the early stage of environmental design to reduce the costs of rehabilitation of the area. Any space should be bright and avoid any entrapment area for crime prevention. It comprised the visibility and design of fence, wall, landscape and housing orientation. Any fencing and wall design should be transparent and caused challenging to mount so it can stimulate natural surveillance and defensible space. People can spot any suspicious movement if it is an access of a judge from the outside. It also enjoyed monitoring the neighbouring area if there is no entrapment space. Based on the findings, as revealed in Table $3,60 \%$ of the house affected by crime before have a very transparent fence, while $20 \%$ is clear with little concealed. Besides, almost $20 \%$ show poor visibility with partially concealed. Higher visibility of fence not based on the transparency of design only but also height above the ground. The units comprise $40 \%$ fence with a height exceeding $5 \mathrm{ft}$. Based on the CPTED implementation guide, any fence should design with not exceeding the limit (5 feet). The reason is to increase the visibility from different sightline to simplify monitoring and viewing by neighbour or residents. Reduced visibility of the fence could block any view of suspicious activity. A criminal can enter and have time to break either door or windows with no difficulty from the outside.

The visibility scale used on fence applied on the inventory's scale of the existent landscape to measures the quality of the view from the outside. As a result, over $43 \%$ of the involved unit has a highly transparent look, while $27 \%$ showed as transparent. Another $29 \%$ of units have shown the visibility with appearing gloomy, partially concealed, and heavily landscaped. In crime prevention, any element of the soft and hard landscape provided must not obscure the sightline. Comply with the guideline of the National Landscape Department; the suggested minimum height of smaller branches should be 2.0 meter ( $6 \mathrm{ft})$ above ground. Besides, any small plant (shrub) should not be higher than 0.9 meters ( $3 \mathrm{ft})$. The landscape which self-prepared inside the home and high dense with neglecting the guideline would also minimise the sightline thus risk bringing into a target. 
Table 3: The element of visibility on each house

\begin{tabular}{|c|c|c|c|}
\hline \multicolumn{2}{|c|}{ Housing Orientation } & \multicolumn{2}{|c|}{$\begin{array}{l}\text { Quality of view from the outside } \\
\text { (landscape) }\end{array}$} \\
\hline Facing each other & $57(50 \%)$ & Very transparent & $49(43 \%)$ \\
\hline $\begin{array}{l}\text { Facing detached/semi- } \\
\text { Detached }\end{array}$ & $17(15 \%)$ & Transparent & $31(27 \%)$ \\
\hline Facing open space & $20(18 \%)$ & Low-transparent & $23(20 \%)$ \\
\hline Facing building side & $19(17 \%)$ & Opaque & $10(9 \%)$ \\
\hline Total & $113(100 \%)$ & Total & $113(100 \%)$ \\
\hline \multicolumn{2}{|c|}{ Fence Height } & \multicolumn{2}{|c|}{ Fence Transparency } \\
\hline Height exceeding $5 \mathrm{ft}$ & $45(40 \%)$ & Very transparent & $68(60 \%)$ \\
\hline \multirow{3}{*}{ Height lower than $5 \mathrm{ft}$} & \multirow{3}{*}{$68(60 \%)$} & Transparent & $23(20 \%)$ \\
\hline & & Low-transparent & $11(10 \%)$ \\
\hline & & Opaque & $11(10 \%)$ \\
\hline Total & $113(100 \%)$ & Total & $113(100 \%)$ \\
\hline
\end{tabular}

The subsequent inventory carried out to identify the degree of intervisibility based on the orientation of houses (Table 3). In this research, the gate entrance of the housing unit that is dealing with other considers having good intervisibility while facing the open space and building side expected to have a low risk of crime. It is an approach to reducing the criminal's confidence to commit a crime when there are high monitoring and surveillance. Therefore, the orientation of the building can create housing to visualise. In crime prevention, any building design should provide space that is open, unhidden and with high visibility. The reason is the orientation of the building considered facilitating natural control and surveillance of the public (street user). People can identify any unusual circumstance in the territory while monitoring in many angles. Even though facing each other can aid the dweller by monitoring and surveillance, but the result shows contradiction. Based on the inventory, $65 \%$ of the affected houses placed facing each other while $35 \%$ dealing with open space and building side. 
Fazzami Othman, Zaharah Mohd Yusoff, Siti Aekbal Salleh

The Impact of Physical Features and Environment on Crime in Urban Neighbourhood Areas

The disparities of findings should also consider the actual crime pattern. As to confirm, most of the crime event took part when there are low people available at home because of daily routine activity. The lack of people in the neighbourhood would lower the potential of monitoring, even if the housing comprises proper monitoring and surveillance system. Therefore, higher surveillance and visibility in building orientation is ineffective if the burglary activity took over when there are low numbers of people in the neighbourhood area.

Housing with higher visibility looks unsafe in these two neighbourhoods. It has not aligned with a CPTED proposition that crime can prevent with excellent visibility. However, a distinct crime and behaviour is something that needs to consider when studying crime and environmental design. As shown in the next analysis, most of the houses that comprise higher-visibility provide a high preventive measure, as shown in Table 4 . In the analysis, the housing is allocating into a distinct group of visibility level. Any unit of the house which recorded fewer than $50 \%$ of visibility is considering low, while over $50 \%$ is high. Besides, based on the inventory, $30 \%$ of burglary happened at the low visibility of the house comprises low transparency, opaque and not facing each other (natural surveillance). This analysis used a statistical correlation to identify the substantial correlation between both variables (visibility and preventive measure). As a result, most of the units in Taman Gembira, which comprise high visibility having more initiative to increase the safety level by applied higher security on the primary access such as the deadlocks and grilles on the door.

Table 4: Security measures taken for crime prevention

\begin{tabular}{|c|c|c|c|c|c|c|}
\hline \multirow{3}{*}{ Preventive Measures } & \multicolumn{3}{|c|}{ Taman Gembira } & \multicolumn{3}{|c|}{ Taman OUG } \\
\hline & \multirow{2}{*}{$\begin{array}{c}\text { Total } \\
\text { Available }\end{array}$} & \multicolumn{2}{|c|}{$\begin{array}{c}\text { Visibility } \\
\text { Level }\end{array}$} & \multirow{2}{*}{$\begin{array}{c}\text { Total } \\
\text { Available }\end{array}$} & \multicolumn{2}{|c|}{$\begin{array}{l}\text { Visibility } \\
\text { Level }\end{array}$} \\
\hline & & High & Low & & High & Low \\
\hline Deadlocks door & 47 & 33 & 14 & 59 & 42 & 17 \\
\hline Front lighting & 39 & 19 & 20 & 40 & 37 & 13 \\
\hline $\begin{array}{l}\mathrm{CCTV} / \text { surveillance } \\
\text { camera }\end{array}$ & 0 & 0 & 0 & 0 & 0 & 0 \\
\hline Burglar alarm & 0 & 0 & 0 & 0 & 0 & 0 \\
\hline Guard dogs & 12 & 2 & 10 & 6 & 2 & 4 \\
\hline Grilles on door & 47 & 40 & 7 & 60 & 51 & 9 \\
\hline $\begin{array}{l}\text { Bars/grilles on } \\
\text { windows }\end{array}$ & 33 & 15 & 18 & 27 & 13 & 14 \\
\hline
\end{tabular}

Besides, in Taman OUG, the same preventive measure taken for high visibility in Taman Gembira, including the front lighting. In distinction, the 
security measure chosen by the low visibility unit in Taman Gembira was the front lighting to enhance the visibility during midnight. Other than that, grilles on windows, deadlocks door and guard dogs were the various actions had for crime prevention. In Taman OUG, deadlocks door, grilles on the window and front lighting were the prevention actions that have applied while some seen to applied guard dogs and grilles on the door. Based on the statistical relationship between visibility and preventive measures taken, both Taman Gembira and Taman OUG shows a significant relationship with $\mathrm{R}^{2}=0.88$, and $\mathrm{R}^{2}=0.95$. In contrast, the variable test for the low visible unit and preventive measure registered value of $\mathrm{R}^{2}=0.51$, and $\mathrm{R}^{2}=0.68$ (Figure 5). To understand, most of the house comprise higher-visibility recorded more burglary incident; thus, taking more preventive measure for crime reduction.

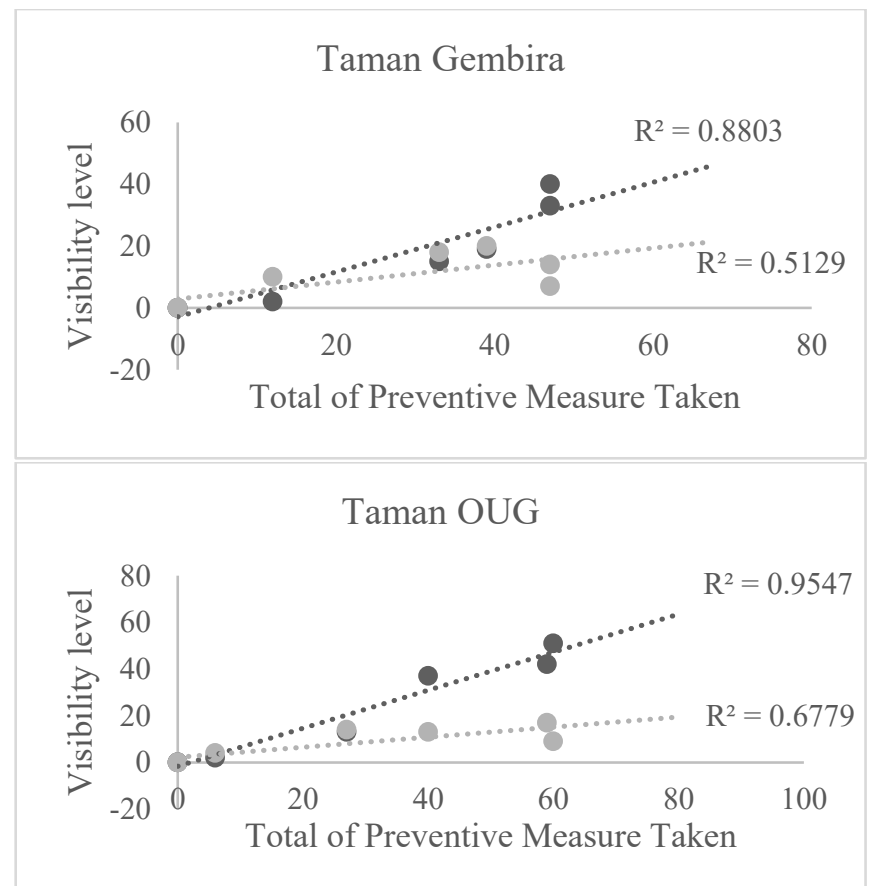

Figure 5: Relationship between visibility and preventive measure taken

Accessibility could be one component that can influence the burglary event in the neighbourhood. It would provide the opportunity for the criminals to break into the house if that feature went on with no consideration. Some potential feature found at the neighbouring dwelling such as stairs, utility poles, fence and trees. Criminal can use these tools that facilitate the criminal to produce illegal activity. In this study, as measured to both neighbourhood, most of the affected 
Fazzami Othman, Zaharah Mohd Yusoff, Siti Aekbal Salleh

The Impact of Physical Features and Environment on Crime in Urban Neighbourhood Areas

house comprised stairs at the back lane (Figure 6). They created the features for usable at the back lane. Almost 39\% unit of the house at Taman Gembira showed at least one stair, while $62 \%$ at Taman OUG (Table 5).

Table 5: Identification of features that invite crime

\begin{tabular}{cccc}
\hline Potential Features & Taman Gembira & Taman OUG & Total \\
\hline Stairs & $20(39 \%)$ & $34(62 \%)$ & 54 \\
Utility Poles & $8(16 \%)$ & $13(23 \%)$ & 21 \\
Trees & $4(8 \%)$ & $1(2 \%)$ & 5 \\
Grilles & $19(37 \%)$ & $7(13 \%)$ & 26 \\
\hline Total & 51 & 55 & 106 \\
\hline
\end{tabular}

Other than that, grilles recorded many at Taman Gembira with $37 \%$ recorded compared to Taman OUG with $13 \%$. As expected, this feature also identifies at the back lane where it attached to window and door at the back. Even though grilles help to enhance safety and prevention, somehow, that feature can use as a climbing tool to go on to the second floors (with the multi-storey house). When both features can extract by itself, one thing that places permanently is utility poles. Besides, utility poles (telecommunication poles) found at the back and side of the house (Figure 6). If the feature spotted with some distance, thus the opportunity would deteriorate. Besides, $8 \%$ of the affected unit in Taman Gembira comprise potential elements of trees while only $2 \%$ at Taman OUG. Almost 77 stairs and utility poles identified on the affected unit of a house in both neighbourhood areas. Most of the potential features that perform as an opportunity for criminal can discover at the back lane. 

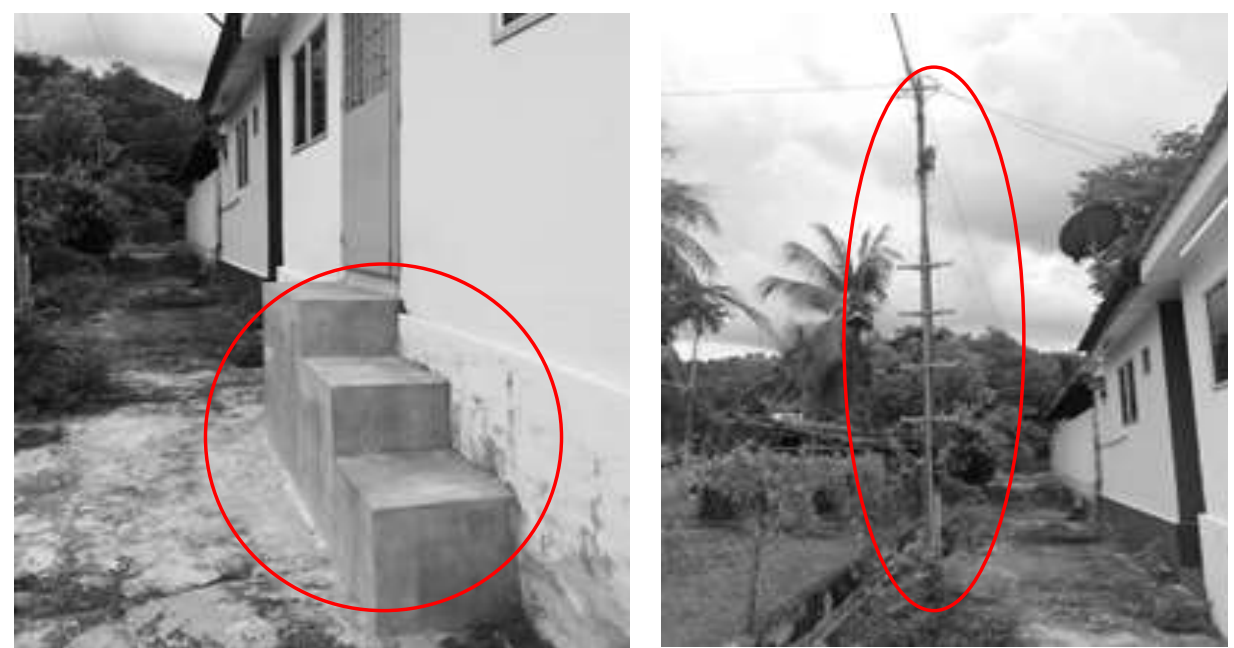

Figure 6: Stairs and utility poles become a tool for criminals to break into houses

\section{CONCLUSION}

This study has shown a level of fear and relationship between actual crime event with environmental design. The respondents' level of fear that changing over the period has supported the data released by the Australian Capital Territory, where the pattern of crime was a regular peak in the early morning and recorded low during midnight (Felson \& Boba, 2010). Perhaps, the mild and deeper environment during the night, which limit the viewpoint, caused the increase of fear level and wrong perception against actual burglary data. The environment factors and mechanical prevention used could influence the level of fear and crime prevention. At least one mechanical surveillance and preventive measure applied to each house as an effort for crime prevention. The initiatives taken bring assumptions that they still fear for repeating as a victim.

In this study, the house with more transparency still affected by high burglary event. This finding reinforces the study by Piza (2019), Kim (2019), and Rosser (2017), which propose the visibility of space influenced the crime rate and fear of crime. As a result, it recommends considering the crime pattern that relates to routine activity when higher visibility is insufficient to prevent the burglary event. The higher crime events happened when there is a low number of people. It caused low monitoring even though higher-visibility comprises to each house. Another feature that can increase burglary incidents is the component of accessibility. Any potential features would present the opportunity for the criminals to break into the house. The study shows that stairs and utility poles at the back lane were the most likely feature that impressed crime in both neighbourhood areas. Thus, well controls and maintain that area by the owner and neighbourhood can reduce the rate and fear of crime. Perhaps, restrict access 
Fazzami Othman, Zaharah Mohd Yusoff, Siti Aekbal Salleh

The Impact of Physical Features and Environment on Crime in Urban Neighbourhood Areas

at the back lane, and side lanes with the installation of the temporary bollards and CCTV can monitor the entrance.

In consequence, fear of crime and perception of risk from being a victim was essential to explore before any micro-level study on crime prevention conducted. In terms of social prevention of property crime, people should have an awareness of the crime pattern in the neighbourhood. No discrepancy between the fear and actual crime pattern, so that the reasonable opportunity to crime reduced. Enhance and controls the potential accessibility, avoid any upgraded features that could reduce the visibility and installing target-hardening was the perfect prevention in the brief terms. It applies to analyses the risk of a neighbourhood with consideration of safety to hold sustainable development. Thus, this research can help as a preliminary study towards better layout design.

\section{ACKNOWLEDGEMENT}

The authors would like to thank Universiti Teknologi MARA (UiTM) for the support and funding the study through the FRGS grant (600IRMI/FRGS/3(205/2019)). The authors would also like to thank the Royal Malaysia Police, surveying sciences and geomatics departments, and individuals who had involved and contributed to this study.

\section{REFERENCES}

Brantingham, P. J., Brantingham, P. L., \& Andersen, M. A. (2017). The Geometry of Crime and Crime Pattern Theory. Journal of Environmental Criminology and Crime Analysis, 98-115.

Bruinsma, G., \& Johnson, S. D. (2018). The Oxford Handbook of Environmental Criminology. United Kingdom: Oxford University Press.

Ceccato, V., \& Uittenbogaard, A. C. (2014). Space-Time Dynamics of Crime in Transport Nodes. Annals of the Association of American geographers, 131-150.

Cozens, P., \& Love, T. (2015). A Review and Current Status of Crime Prevention through Environmental Design (CPTED). Journal of Planning Literature, 30(4).

Department of Town and Country Planning. (2012). Crime Prevention Through Environmental Design (CPTED): Implementation Guide. Kuala Lumpur: Unit Khas NKRA Bandar Selamat.

Du, Y., \& Law, J. (2016). How Do Vegetation Density and Transportation Network Density Affect Crime across an Urban Central-Peripheral Gradient? A Case Study in Kitchener-Waterloo, Ontario. Journal of Geo-Information, 118.

Felson, M., \& Boba, R. (2010). Crime and Everyday Life. United Kingdom: Sage Publications, Inc UK.

Google (2020). Google maps. Retrieved April, 2020, from http://maps.google.com.my

Kim, D., Hong, S. W., \& Jeong, Y. (2016). Crime prevention effect of the secondgeneration crime prevention through environmental design project in South Korea: an analysis. Journal of Social Science, 12.

Lee, S., \& Ha, M. (2016). The effect of visibility on fear of crime in schools' interior environments. Journal of Asian Architecture and Building Engineering, 527-534. 
Lis, A., Pardela, L., Can, W., Katlapa, A., \& Abalski, L. R. (2019). Perceived Danger and Landscape Preferences of Walking Paths with Trees and Shrubs by Women. Sustainability Journal, 45-65.

Malleson, N., \& Andresen, A. (2015). Spatio-temporal crime hotspots and the ambient population. Crime Science, 4:10.

Marzbali, M. H., Abdullah, A., \& Tilaki, M. J. (2019). Crime Prevention Through Environmental Design (CPTED) in Malaysia: Strengthening the Links with Crime Science. In Rebuilding Crime Prevention Through Environmental Design (pp. pp.153-183).

Patterson J. L. (2016). Traffic modelling in cities - Validation of space syntax at an urban scale. Indoor and Built Environment, Vol. 25(7) 1163-1178.

Piza, E. L., Welsh, B. C., Farrington, D. P., \& Thomas, A. L. (2019). CCTV surveillance for crime prevention. Journal of criminology \& public policy, Volume 18, issue 1.

Royal Malaysia Police (2018). Burglary Indeks in Kuala Lumpur Year 2015 - 2017. Retrieved March 12, 2018, from Official Portal of Royal Malaysia Police: http://www.rmp.gov.my/

Rosser, G., \& Davies, T. (2017). Predictive Crime Mapping: Arbitrary Grids or Street Networks? Journal of Quantitative Criminology, Volume 33, Issue 3, pp 569-594.

Ryan J. (2014, July 10). What is CPTED, and how can it help your community? Retrieved from Bureau of Justice Assistance: http://bjatta.bja.ojp.gov

Schroeder, T., \& Saboya, R. T. (2015). Configurational characteristics of socio-spatial segregation in Brazilian cities. Brazil.

Shamsuddin, S., \& Hussin, N. A. (2013). Awareness by Kuala Lumpur City Hall Staffs for Successful Implementation of Crime Prevention Through Environmental Design (CPTED). Journal of the Malaysia Institute of planners, 41-58.

Summers, L., \& Johnson, S. D. (2017). Does the Configuration of the Street Network Influence where Outdoor Serious Violence Takes Place? Using Space Syntax to Test Crime Pattern Theory. Journal of quantitative criminology, Vol 33, 397 - 420.

Received: $15^{\text {th }}$ May 2020. Accepted: $1^{\text {st }}$ Sept 2020 